UNITED STATES

PARTMENT OF

JMMERCE

IBLICATION

National Bureau of Standards

Library, E-01 Admin. Bldg.

AUG $18 \quad 1970$

Referserica bon's not io :3 taken rrom the library.

BUILDING SCIENCE SERIES

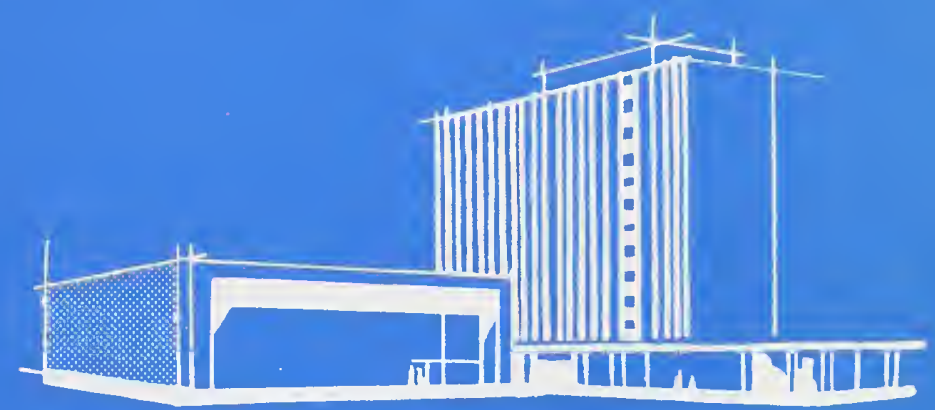

U.S. PARTMENT

TA 435 .458 No.3! 1970 copy 1.

\title{
Flexural Behavior \\ of \\ Concrete \\ Composite Tee-Beams
}


The "Building Science Series" disseminates technical information developed at the Bureau on building materials, components, systems, and whole structures. The series presents research results, test methods, and performance criteria related to the structural and environmental functions and the durability and safety characteristics of building elements and systems.

These publications, similar in style and content to the NBS Building Materials and Structure Reports (1938-59), are directed toward the manufacturing, design, and construction segments of the building industry, standards organizations, officials responsible for building codes, and scientists and engineers concerned with the properties of building materials.

The material for this series originates principally in the Building Research Division of the NBS Institute for Applied Technology. Published or in preparation are:

BSS0. Building Research at the National Bureau of Standards. (In press)

BSS1. Performance of Buildings-Concept and Measurement. Man and His Shelter. \$2.75

BSS2. Interrelations Between Cement and Concrete Properties: Part 1, Materials and Techniques, Water Requirements and Trace Elements. 35 cents

BSS3. Doors as Barriers to Fire and Smoke. 15 cents

BSS4. Weather Resistance of Porcelain Enamels: Effect of Exposure Site and Other Variables After Seven Years. 20 cents

BSS5. Interrelations Between Cement and Concrete Properties: Part 2, Sulfate Expansion, Heat of Hydration, and Autoclave Expansion. 35 cents

BSS6. Some Properties of the Calcium Aluminoferrite Hydrates. 20 cents

BSS7. Organic Coatings. Properties, Selection, and Use. $\$ 2.50$

BSS8. Interrelations Between Cement and Concrete Properties: Part 3, Compressive Strengths of Portland Cement Test Mortars and Steam-Cured Mortars. 55 cents

BSS9. Thermal-Shock Resistance for Built-Up Membranes, 20 cents

BSS10. Field Burnout Tests of Apartment Dwelling Units. 25 cents

BSS11. Fire Resistance of Steel Deck Floor Assemblies. 25 cents

BSS12. Performance of Square-Edged Orifices and Orifice-Target Combinations as Air Mixers. 15 cents

BSS13. Shrinkage and Creep in Prestressed Concrete. 15 cents

BSS14. Experimental Determination of Eccentricity of Floor Loads Applied to a Bearing Wail. 15 cents

BSS15. Interrelations Between Cement and Concrete Properties: Part 4, Shrinkage of Hardened Portland Cement Pastes. 75 cents

BSS16. Techniques for the Survey and Evaluation of Live Floor Loads and Fire Loads in Modern Office Buildings. 40 cents

BSS17. Causes of Variation in Chemical Analyses and Physical Tests of Portland Cement. 40 cents

BSS18. Smoke and Gases Produced by Burning Aircraft Interior Materials. 35 cents

BSS19. A Study of the Variables Involved in the Saturating of Roofing Felts. 30 cents

BSS20. Proceedings of a Seminar on the Durability of Insulating Glass. 75 cents

BSS21. Algorithms for Psychrometric Calculations. 55 cents

BSS22. Investigation of Performance Characteristies for Sanitary Plumbing Fixtures. 70 cents

BSS23. Hail Resistance of Roofing Products. 25 cents

BSS24. Natural Weathering of Mineral Stabilized Asphalt Coatings on Organic Felt. 30 cents

BSS25. Structural Performance Test of a Building System. $\$ 1.25$

BSS26. Radiation Errors in Air Ducts Under Nonisothermal Conditions Using Thermocouples, Thermistors, and a Resistance Thermometer. 25 cents

BSS27. Performance of Louvered Devices as Air Mixers. 30 cents

BSS28. Exploratory Studies of Early Strength Development in Portland Cement Pastes and Mortars. (In press)

BSS29. 1964 Exposure Test of Porcelain Enamels on Aluminum-Three Year Inspection. 25 cents

BSS30. Wind Loads on Buildings and Structures. Proceedings of a Technical Meeting, NBS, Gaithersburg, Md., January 27-28, 1969. (In press)

Send orders wtih remittance to: Superintendent of Documents, U.S. Government

Printing Office, Washington, D.C. Remittances from foreign countries should include an additional one-fourth of the purchase price for postage.

[See mailing list announcement on last page.] 


\title{
Flexural Behavior of Prestressed Concrete Composite Tee-Beams
}

\author{
J. O. Bryson and E. F. Carpenter \\ Building Research Division \\ Institute for Applied Technology \\ National Bureau of Standards \\ Washington, D.C. 20234
}
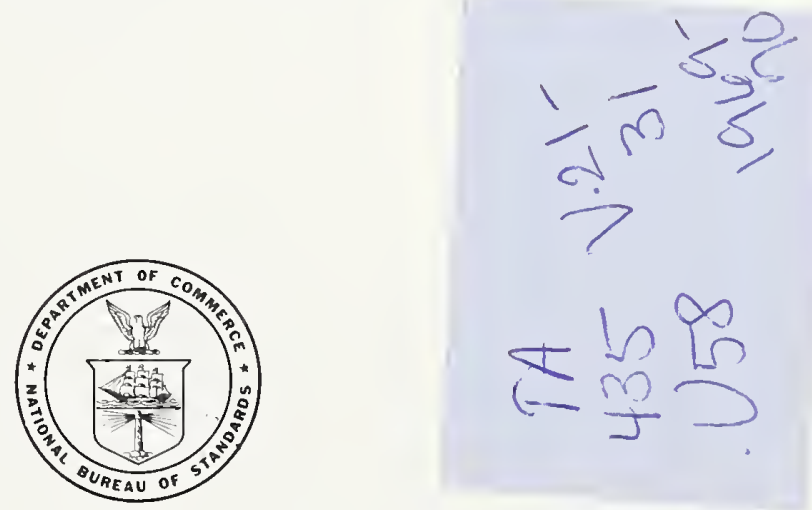

\section{U.S.Nationd Buradu t Standards.}

Building Science Series 31

Nat. Bur. Stand. (U.S.), Bldg. Sci. Ser. 31, 14 pages (July 1970)

CODEN: BSSNB

Issued July 1970

For sale by the Superintendent of Documents, U.S. Government Printing Office

Washington, D.C. 20402 (Order by SD Catalog No. C $13.29 / 2: 31$ ), Price 25 cents 
MATIONAL BURENU OF STK

\section{Contents}

1. Introduction

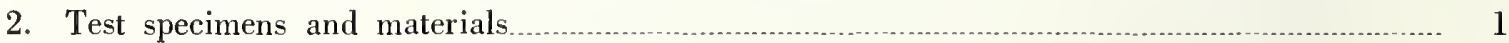

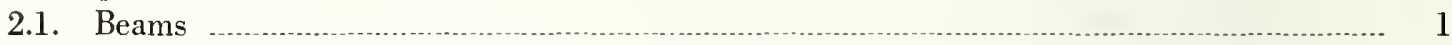

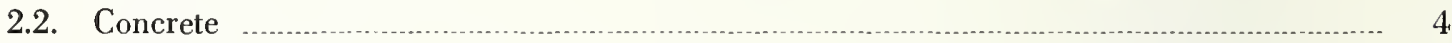

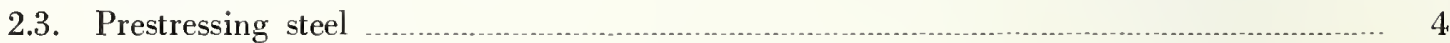

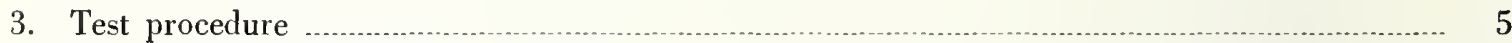

4. Test results and analysis

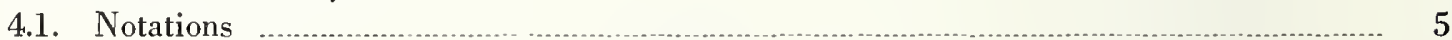

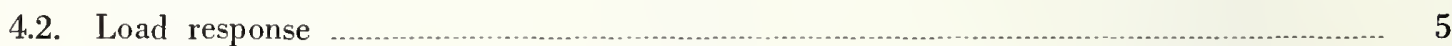

4.3. Ultimate strength _............. 7

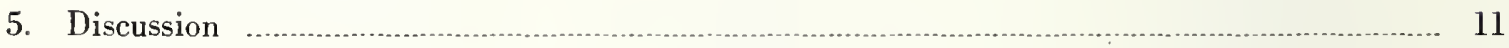

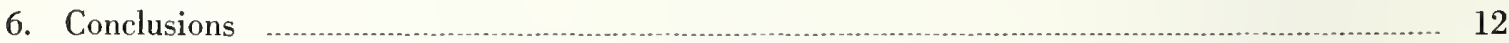

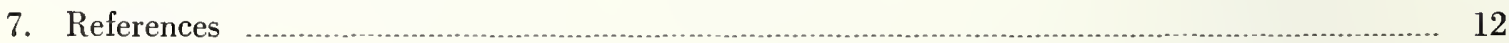




\title{
Flexural Behavior of Prestressed Concrete Composite Tee-Beams
}

\author{
J. O. Bryson and E. F. Carpenter
}

\begin{abstract}
Prestressed Tee-beams constructed by the split-beam method were tested to failure in flexurc to study the behavior and ultimate strength of these beams and to compare their flexural characteristics with those of prestressed beams of conventional construction. The compressive portion of the cross section of the split-beam is cast after the web of the beam has been formed and pre. stressed. The variables in the study included the percentage of prestressing steel, strength of concrete in the compressive element of the composite split-beams, manner of prestressing and wel, reinforcement.
\end{abstract}

Results showed that the composite split-beams behaved similarly to the monolithically constructed beams on the basis of flexural response and ultimate load. The strength of the concrete for the compressive element can be reduced within limits from that required for the prestressed element without sacrificing ultimate load capacity. The required percentage of reinforcing stecl is less for the split-beam compared with conventional beams.

Key words: Composite concrete construction; prestressed concrete beams; Tee-beams.

\section{Introduction}

A notable departure from the usual concept of composite prestressed concrete design was developed several years ago by A. Amirikian [1] ${ }^{1}$ of the U.S. Department of the Navy. The principal objective of the Amirikian concept is to optimize the application of prestressing for flexural concrete members by prestressing only the area of the cross section normally subjected to tension under bending. This requires that the tensile and compressive areas of the beam's cross section be constructed separately in order to restrict the precompression of the concrete to the tensile section. Therefore, this procedure can be considered as a special case of composite construction in which the interface of the two elements is set at the neutral axis of the composite section instead of at the junction of the flange and web as in normal composite construction. Beams constructed by this procedure are called "split-beams" and feature reduced prestressing forces for the same working load capacity compared with similar beams of conventional design.

A series of prestressed Tee-beams constructed by the split-beam technique were tested to failure to study the behavior and ultimate strength of these beams and to compare their performances with those of conventional monolithic prestressed beams. The variables in the study included the percentage of prestressing steel, strength of concrete in the compressive element of the split-beam, manner of prestressing, and web reinforcement.

The work reported here is an extension of an earlier study [2] with split-beams of rectangular cross section. With the rectangular beams the principal difference between the split-beam and conventional beam was in the required prestressing force and location of the prestressing tendon in the cross section. The crosssectional properties of Tee-beams lend themselves to an additional advantageous feature in the split-beam technique. With Tee-beams under flexural loading the strain on the compressive surface (top of the flange) is usually considerably less than that on the tensile surface (bottom of the stem) due to the position of the elastic neutral axis. This means that the strength of the concrete in the flange section, provided to resist compressive stresses, need not be as high as that re. quired in the tensile section which is initially cast and prestressed. This allows for savings in materials.

\section{Test Specimens and Materials}

\subsection{Beams}

The concept of split-beam design takes advantage of the technique of composite construction for minimiza. tion of the prestress in the cross section. The design

\footnotetext{
${ }^{1}$ Figures in brackets indicate the literature reference at the end of this paper.
} 
procedure is to determine the overall cross section for the beam as would be done for a conventional monolithic prestressed beam. From the properties of the full cross section, the area that will experience tension under loading is defined by the location of the elastic neutral axis. This area will be cast separately in the split-beam construction and is termed the tensile element. After prestressing the tensile element, the zone of the split-beam that will resist compression is caston and is practically stress free prior to the application of live load.

The specimens in this investigation included beams of conventional monolithic construction as well as the split-beams of composite construction. They were all Tee shaped in cross section with a 3 -in by 15 -in flange, an overall depth of $18 \mathrm{in}$, and were $19 \mathrm{ft}$ long. The two monolithic beams were post-tensioned while the split-beams included both post-tensioned and pretensioned specimens.

Figure 1 shows the nominal dimensions of the beams with the location of the prestressing tendon in the cross section given for both the monolithic beam and the split-beam. Also, the positions of support and points of loading for tests are indicated. fixed in position at the ends of the form and at the third-point and midspan locations.

A single steel bar, threaded on both ends, was used as the prestressing tendon in the post-tensioned beams. In each case, the tendon was straight and located at a constant depth in the cross section throughout the length of the beam.

Figure 2 shows a tensile element setup for posttensioning. The tensioning force in the tendon was measured with a steel dynamometer attached to the tendon at the end of the beam opposite to the jacking end. This force was distributed over the ends of the prestressed element with 1-in thick bearing plates. Heavy duty steel nuts bore against the dynamometer on one end and the bearing plate on the other end to maintain the prestressing force in the element.

The pretensioned beams were each prestressed with two strands of steel cable. In profile, the strands were straight and parallel and spaced approximately 1 -in center to center in a vertical plane throughout the central $12-\mathrm{ft}$ section of the span of the beam $(6 \mathrm{ft}$ to each side of the midspan section). From these points they spread apart at equal angles to about 3 -in
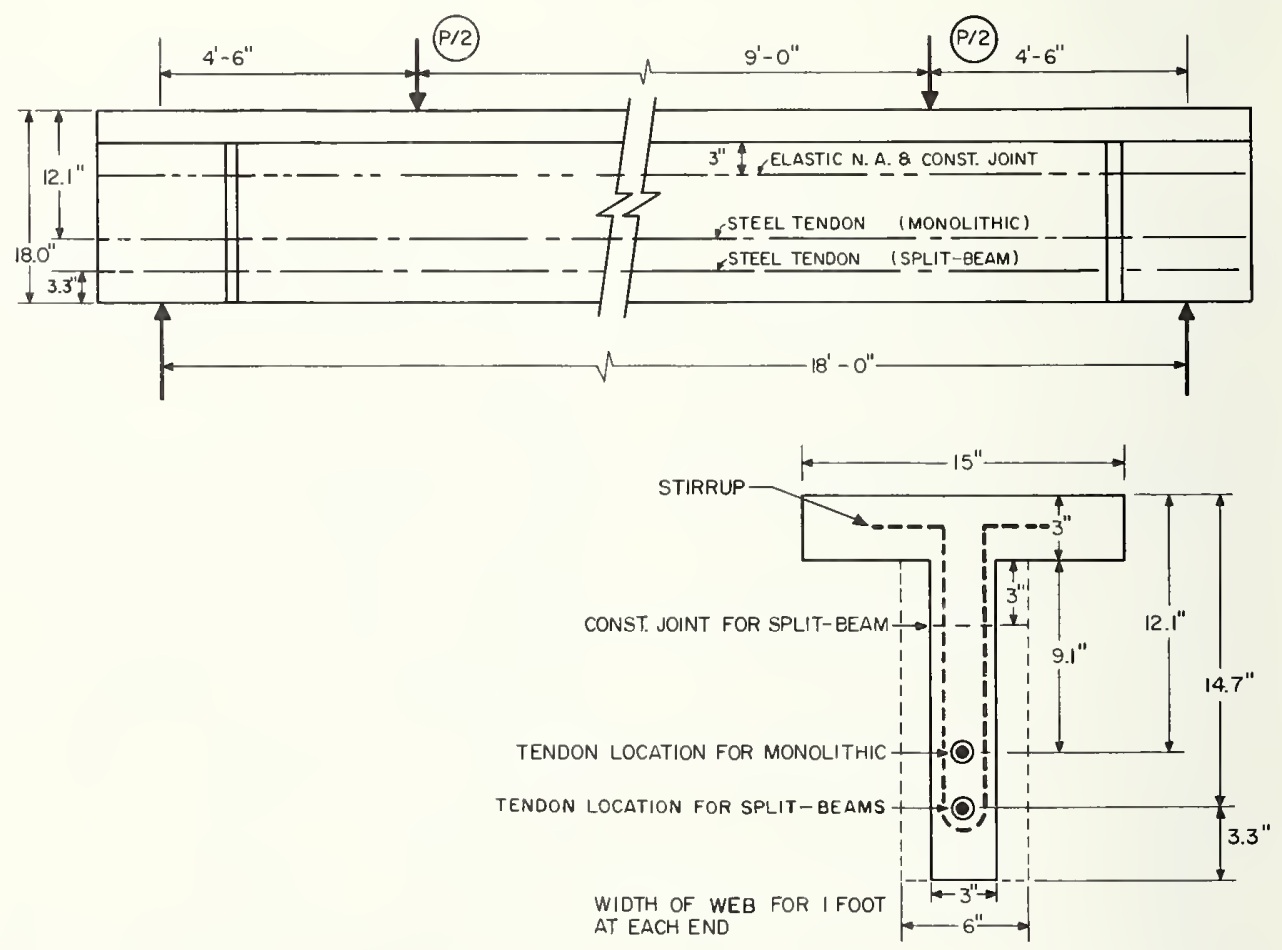

Figure 1. Beam dimensions and loading arrangement.

The channel for the reinforcing tendons in each post-tensioned beam was formed by placing a length of thin-wall steel tubing, 1 -in O.D., with 1/16-in wall thickness, in the form in the position specified for the tendon. The use of this tubing in prestressed beams in an earlier study [2] had no apparent effect on the performance of the beams. The tubing was center to center at the ends of the beam. Steel washers with $11 / 2$-in I.D. were used to accomplish the angle change in the profile of the strands. The washers encircled the strands and were located at the points along the length of the strands where it was desired to change the angles. The two strands were tensioned simultaneously against anchors which spaced them 


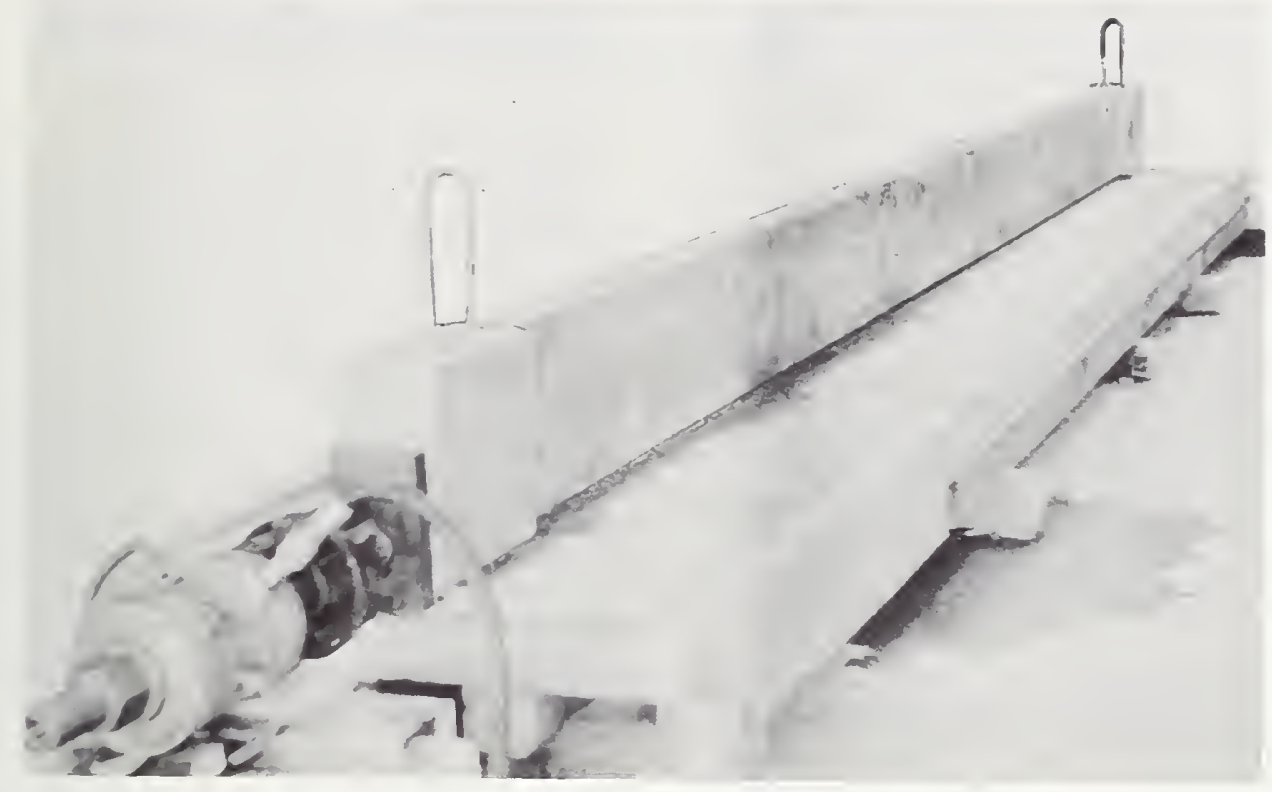

FIGLRE 2. Tensile element with jacking arrangement setup for post-tensioning.

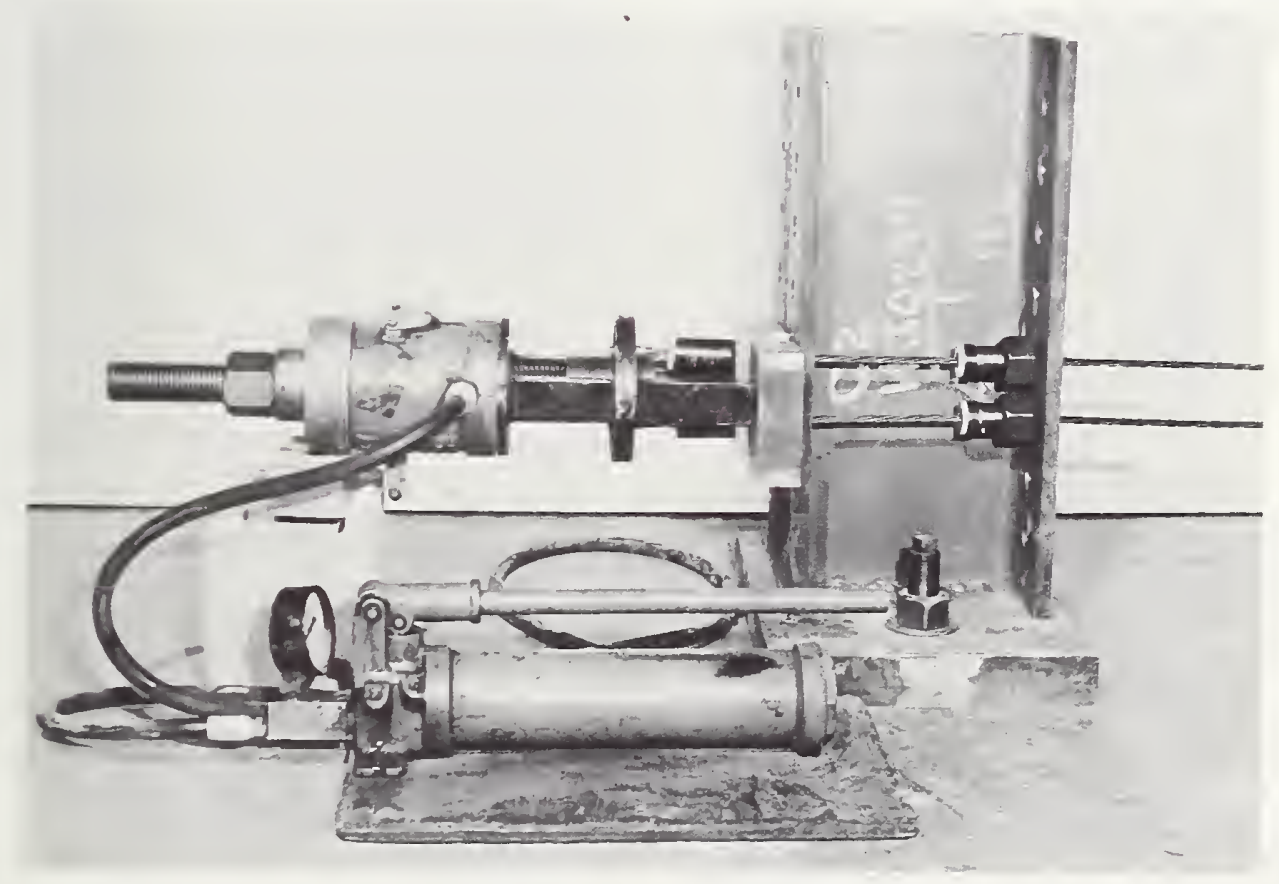

FICURE 3. Jacking arrangement for pretensioning.

about $3 \frac{1}{2}$ in apart. With the washers encircling the strands and located $4 \mathrm{ft}$ away from the pretensioning anchors, the strands, under tension, sloped down to the location of the washers which restrained the spread from these points inward to the 1 -in spacing described above.

A view of the jacking arrangement for pretension- ing is presented in figurc 3 . The pretensioning wires were stressed between two stub columns which were set $25 \mathrm{ft}$ apart and fixed to a tie-down floor. A steel dynamometer was placed between standard chuck type strand grips and the anchoring column at the end opposite to the jacking end to reflect the prestressing force in the strands. 
Stirrups were fabricated from mild steel No. 3 reinforcing bars having a yield strength of 50,000 psi. They were U-shaped in the stem of the beam and placed throughout the span length spaced $1 \mathrm{ft}$ apart. The stirrups looped under the prestressing tendon extended up to the midheight of the flange and out 6 in horizontally on both sides.

The tendon in the monolithic beam was located 6.1 in below the center of gravity for the Tee section and the prestress force was $45,000 \mathrm{lb}$. The location of the tendon in the split-beam was 8.7 in below the center of gravity of its composite Tee section and the prestress force was $27,000 \mathrm{lb}$. The essential difference here is that the location of the tendon and the prestress for the monolithic beam is determined from the properties of the full Tee section while, due to the nature of the construction of the split-beam [2], the location of the tendon and the prestress is determined by the prop-

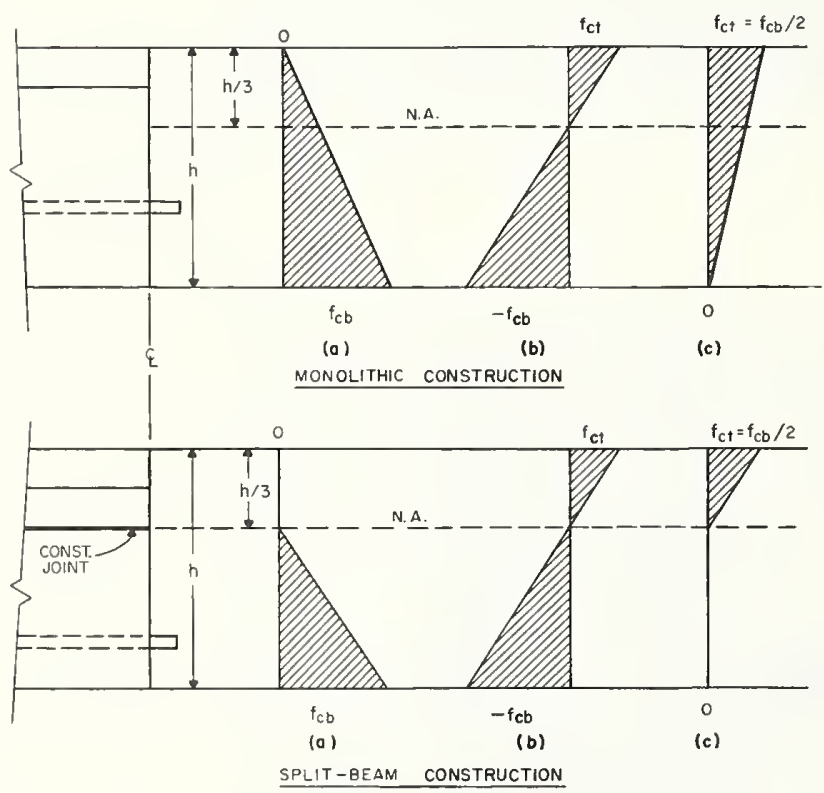

Figure 4. Stress conditions at midspan idealized, (a) after prestress, (b) gradient produced by applied load causing stress at bottom fiber equal to prestress, (c) resultant from combining (a) and (b).

erties of the tensile element of the composite tee section.

Figure 4 shows the idealized stress conditions for both types of beams for two stages of loading. The stress conditions (a) show that for the monolithic beam the stress block tapers from the maximum value at the bottom fiber to zero at the top fiber of the beam. The stress block for the split-beam, for this stage, tapers from the maximum value at the bottom fiber to zero at the neutral axis of the composite section. This difference in the stress blocks reflects the same proportional difference in the required prestressing force for the two types of beams. The value of applied load that will cause zero stress in the bottom fiber is represented by the stress condition (b) and is the same for both the monolithic beam and the split-beam The stress condition (c) results from the combinatior of (a) and (b).

\subsection{Concrete}

The concrete used in the first 12 specimens was composed of Type III portland cement, siliceous sand and pea gravel. This concrete was mixed in the labora. tory in a turbine-type mixer of $1 / 2 \mathrm{cu}$ yd capacity. Concrete for the subsequent beams was obtained from a local ready-mix company using the same materials except for the coarse aggregate which was a Maryland No. 7 crushed lime stone ( size No. 8, ASTM C 33-67). The mix proportions were varied around a design mix for 5000 psi concrete which was $1: 3.2: 2.6$ by weight of cement, sand, and gravel. The water content varied from 6 to 11 gal per sack of cement $(94 \mathrm{lb})$. The concrete strengths at the time of beam testing are given in table 1 . These strengths represent the average values determined from compressive tests of three 6-by-12-in control cylinders.

\subsection{Prestressing Steel}

Two types of steel were used as prestressing tendons. The stress-strain curves for the steels are shown in figure 5. For the post-tensioned beams, high strength heat-treated, stress-relieved bars were used. Tensile tests of these bars indicated a stress-strain relationship that is essentially linear up to a stress of $108,000 \mathrm{psi}$, and an initial tangent modulus of approximately 29.8 x $10^{6}$ psi. The yield strength of the steel was 170,000 psi as determined by the 0.2 percent offset method. The tensile strength was 190,000 psi. The prestressing tendons for the pretensioned beams were 7 -wire strands of high strength steel. Tensile tests of the strands showed a linear stress-strain relationship up to a stress

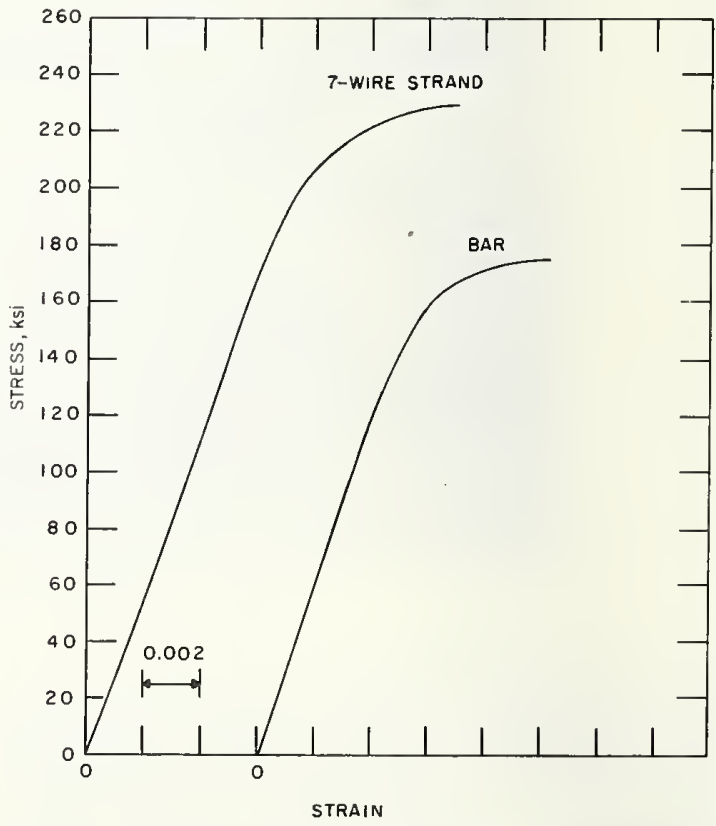

Figure 5. Stress-strain curves for prestressing steel tendons. 
of approximately 162,000 psi. The tangent modulus for the strand was $28.1 \times 10^{6}$ psi. The yield strength was defined at 0.2 percent offset and was 221,000 psi. The ultimate strength of the strands, as could be developed in the beams, was not determined precisely since in all cases the strands fractured in the grips in the tensile tests. However, indications from the tensile test and the beam tests suggest that the manufacturers rating of 250,000 psi is valid.

\section{Test Procedure}

All beams were tested as soon as the desired concrete strengths in the compressive element were reached. The ages of the beams at the time of testing ranged from 10 to 16 days. The specimens were tested to failure with equal loads applied at the quarter points. In general, load increments of $2000 \mathrm{lb}$ were applied except in the range of cracking where increments of $500 \mathrm{lb}$ were used. After the application of each load increment, the deflection of the beam, the force in the reinforcing tendon for unbonded beams, the strain on the concrete surface, and the extent of cracking were recorded. The time required for these readings varied from 3 to $5 \mathrm{~min}$ and the time for the overall test varied from 60 to $90 \mathrm{~min}$. For the pretensioned beams, electrical resistance gages were applied to individual wires of the strands for strain measurements. However, readings from these gages beyond the cracking loads were erratic in all cases and were discarded.

\section{Test Results and Analysis}

\subsection{Notations}

$A_{s}=$ area of main prestressing tensile steel

$b^{\prime}=$ width of flange of Tee section

$b=$ width of web of Tee section

$d=$ distance from extreme compressive fiber to the prestressing force

$f^{\prime}{ }_{c}=$ compressive strength of concrete at time of test

$f_{c b}=$ concrete stress in the bottom extreme fiber of the cross section

$f_{c t}=$ concrete stress in the top extreme fiber of the eross section

$f_{s e}=$ effective steel prestress after losses

$f_{s u}=$ stress in prestressing steel at ultimate load

$f_{s y}=$ nominal yield point stress of prestressing steel

$k_{1}=$ the ratio of average compressive stress to maximum compressive stress

$k_{2}=$ coefficient determining position of internal compressive force (fig. 12)

$k_{3}=$ ratio of compressive strength of concrete in flexure to cylinder strength

$k_{u} d=$ distance from extreme fiber in compression to neutral axis at ultimate load (fig. 12)

$M_{u}=$ maximum beam moment at ultimate load

$P=A_{s} / b d ;$ ratio of prestressing steel

$q_{u}=P f_{s u} / f_{c}^{\prime}$; tension reinforcement index
Values of observed and computed characteristics of the beams are given in Table 1. The first order grouping of the specimens is by methor of prestressing and attachment of tendons. There are three classifications: (1) post-tensioned, unbonded; (2) post-tensioned. grouted; and (3) pretensioncd, bonderl. The two beans with grouted tendons, SG-1 and SG-2, experienced bond failures beyond the cracking loads. Since there are no appreciable differences in the performance of beams with bonded and unbonded tendons prior to the onset of cracking, these beams were classed as unbonded for the purpose of comparison.

The beams in this investigation fall into one of five different steel ratio $(p)$ groups. However, lest results show that a better ordering of groups can be made in terms of a moment index, $A_{s} f_{s y} d$. All beams, except SU-11, SU-14, and SG-2, failed after the yield strength of the reinforcement had been reached. Bcams SU-11 and SU-14 had 1900 psi and 2000 psi coneretes in the compressive zones, respectively, and failed by compression of concrete with the reinforcement in the elastic range. Beam SG-2 failed by interface separation in the shear span.

The performances of the beams are compared in terms of load-deflection characteristics, ultimate strengths, and crack patterns. The moment index $A_{s} f_{s y} d$ shows a direct correlation with both the loaddeflection relationship and ultimate strength. However, the fact should not be overlooked that all beams in this study were of the same shape and size and were tested in the same manner.

\subsection{Load Response}

A flexural load applied on a reinforced eoncrete beam of a given cross section will require a specific

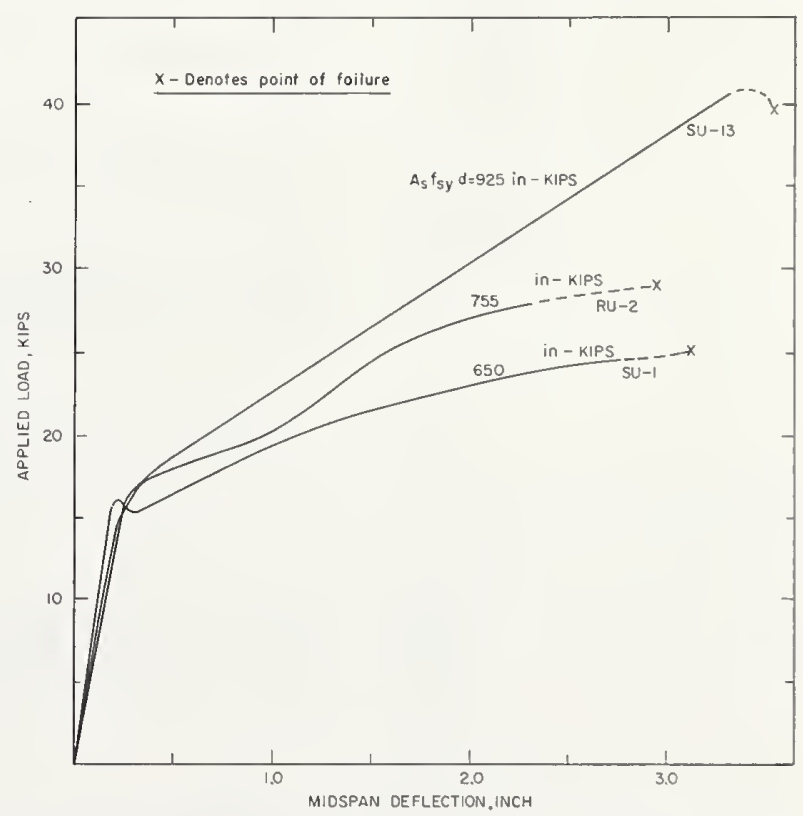

Figure 6. Load-deflection relationship for post-tensioned beams with unbounded solid bar tendons. 


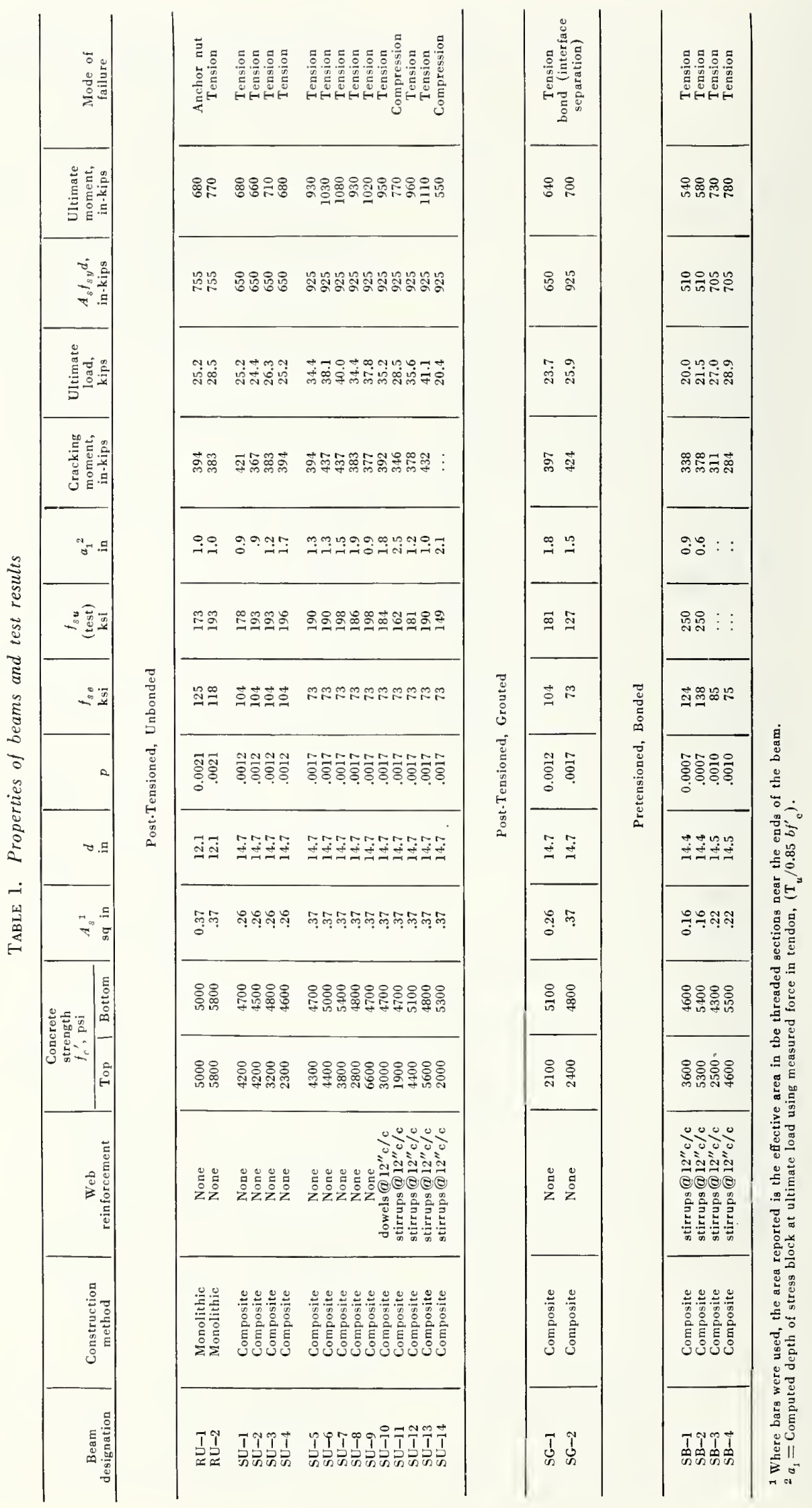


force to act at the level of the steel for equilibrium. In a prestressed beam the strains at the level of the steel are a function of the moment of inertia of the full transformed cross section up to the cracking load. Within this range of loading, the effect of large differences in steel areas on the straining rate at the level of the steel is relatively small. However, once the beam has cracked, the amount of strain in the steel for a given increment of loading will vary inversely with the tendon area.

Typical load-deflection relationships for post-tensioned beams with unbonded solid bar tendons are shown in figure 6 and for pretensioned beams with bonded strand tendons in figure 7 . The three curves representing the post-tensioned beams in figure 6 clearly show the effect of the moment index $\left(A_{s} f_{s y} d\right)$ on the performance of the beams. The same is true for the two curves representing the pretensioned beams in figure 7 . The initial portion of the load deflection for the two groups of beans. Typical crack patterns for the beams are shown in figure 9. For the posttensioned heams, a single crack frrt appeared at or very near midspan and was followed shortly, as loading proceeded, by the development of two or threc additional cracks on both sides of the crack at mirlspan. In beams without stirrups, the midspan crack developed into a distinctive $Y$ pattern with hori. zontal extensions just under the flange covering a large section of the constant moment zone. When stirrups were used in the post-tensioned beams, the horizontal cxtensions of the central crack wcre climinated. Views of a post-tensioned and a pretensioned beam at ultimate load are presented in figures 10 and 11, respectively, to illustrate the differcnce in crack distributions and their cffect on deflection. In all post-tensioned unbonded beams the central crack dominated the failure mode causing the maximum compressive strain in the concretc, and conscquently

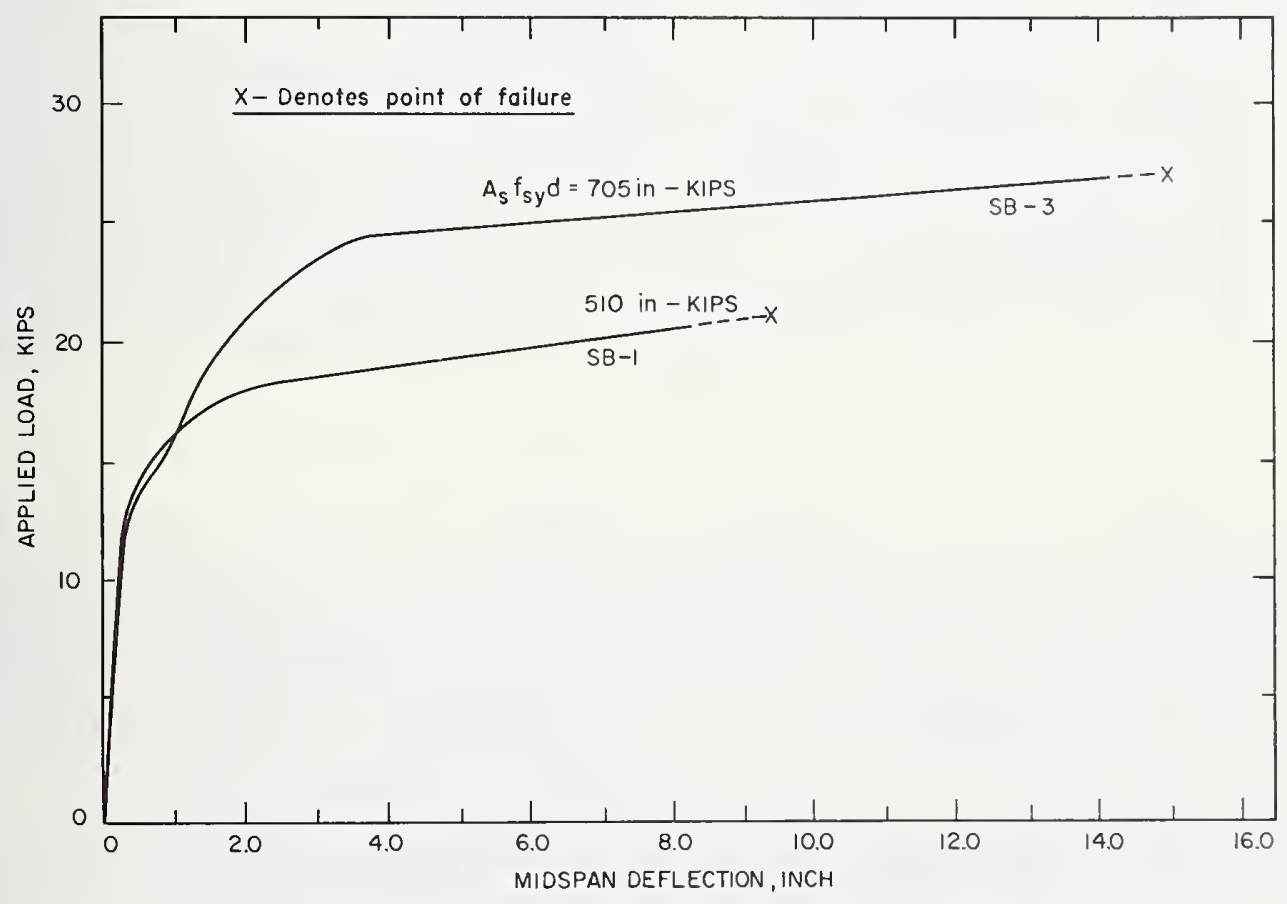

Figure 7. Load-deflection relationship for pretensioned beams with bonded strand tendons.

curves in all cases was a straight line with practically the same slope, irrespective of the moment index. This portion of the curve reflects the response of the beam to loading prior to the onset of cracking. Subsequent to cracking, however, the curves are ordered in accordance with the moment index.

In figure 8 a basic difference is seen in the overall characteristics of the load-deflection curves between the post-tensioned and the pretensioned beam groups. The pretensioned beams (SB-1, SB-3) showed considerably more ductility in their response to loading than the post-tensioned group (SU-1, RU-2, SU-13). Distinctively different crack patterns were observed the maximum curvature of the beam to concentrate at the midspan. For the pretensioned bonded beams, 10 to 12 equally spaced cracks dereloped in the constant moment zone. These cracks propagated and opened with equal magnitude as load increments were added and until failure occurred. This caused a more uniform and greater overall curvature in the pretensioned beams than for the post-tensioned ones.

\subsection{Ultimate Strength}

Final failure in flexure of a reinforced concrete beam may be initiated by excessive elongation of the reinforcement, in which case it is called tension failure, 


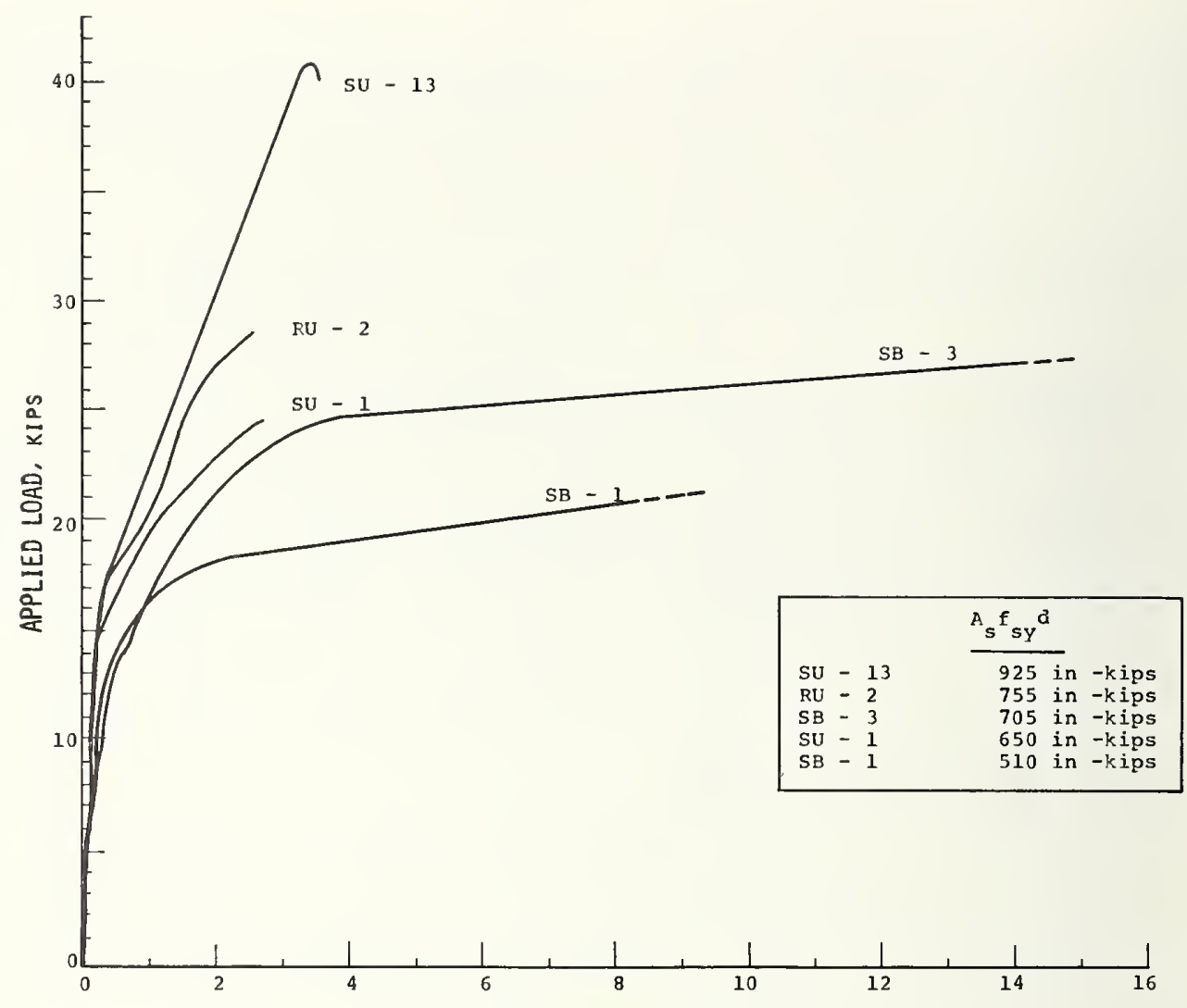

MIDSPAN DEFLECTION, INCH

Figure 8. Combined curves of load-deflection relationship for all methods of prestressing and types and sizes of tendons.

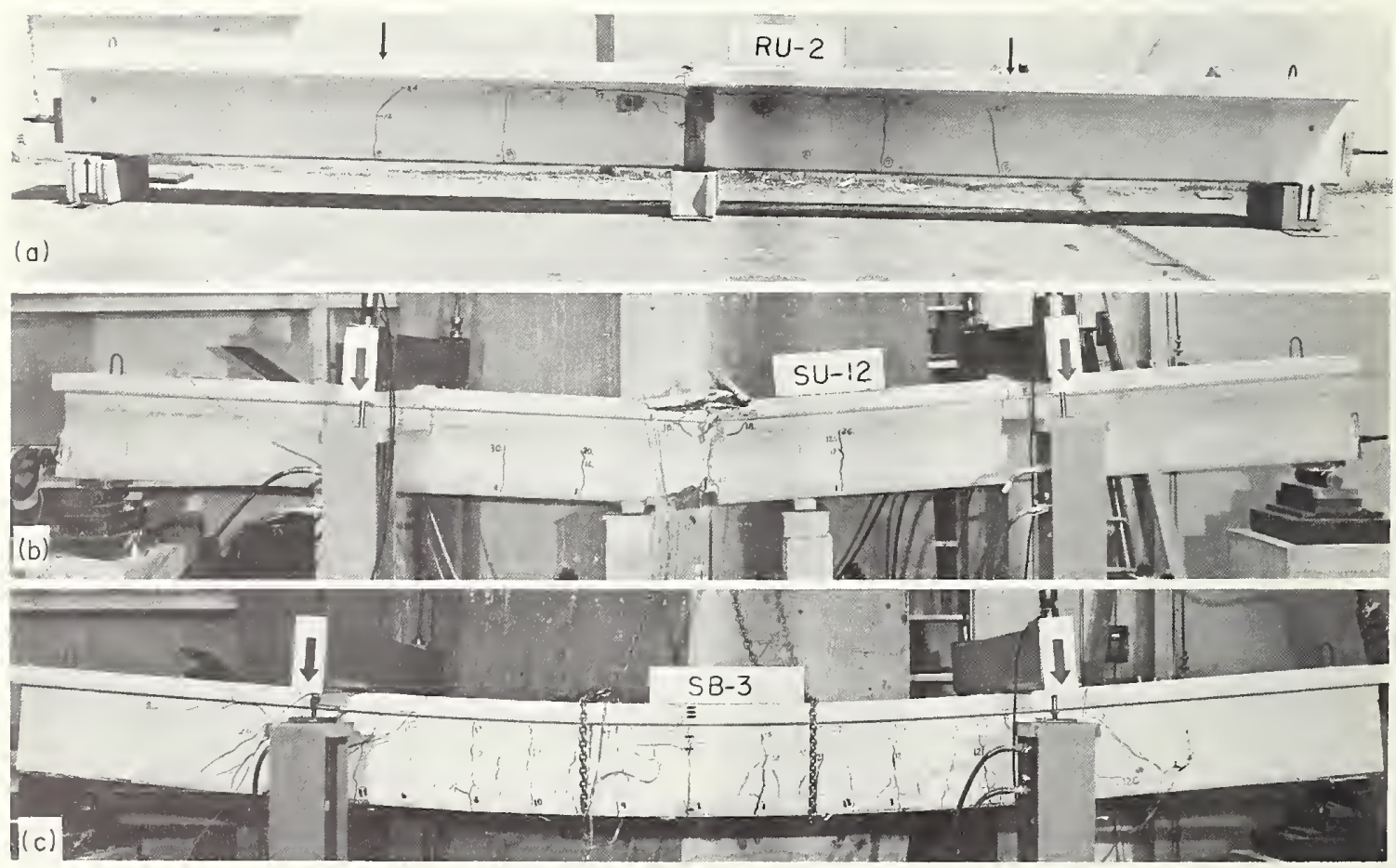

Figure 9. Typical crack patterns for beams: (a) Post-tensioned unbonded without stirrups; (b) post-tensioned unbonded with stirrups; (c) pretensioned bonded. 
or crushing of the concrete may occur before yield of the reinforcement which is termed a compression failure. Other types of failures were of secondary concern in this study. In general, the beams in this inves- tigation failed in tension. Two brams, RU-1 and RU-2, failed prematurely and their results are not used for comparisons in the study. Beam RU-1 failed when the threads in an anchor nut on one end of its

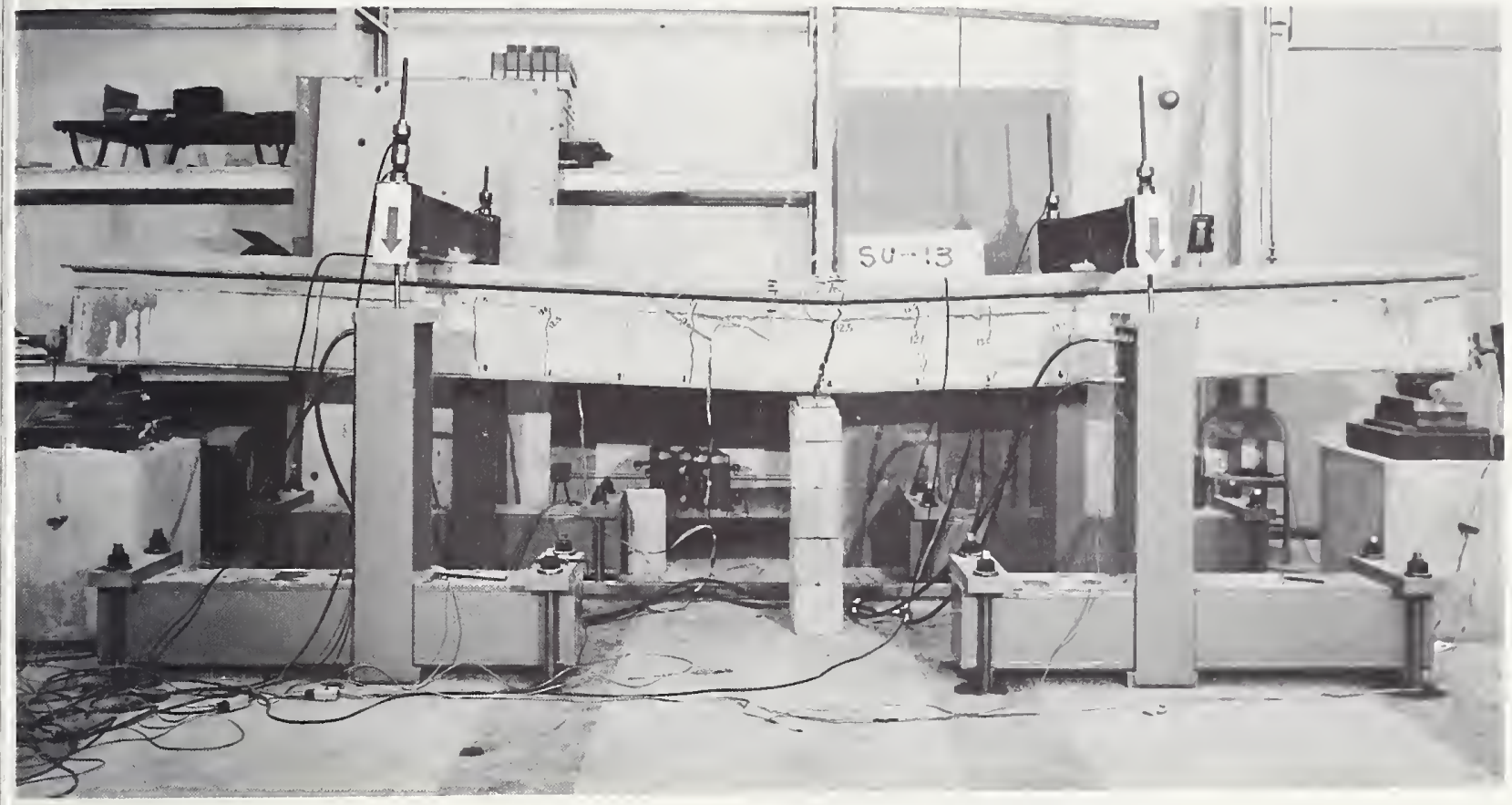

Figure 10. Post-tensioned beam SU-13 at ultimate load.

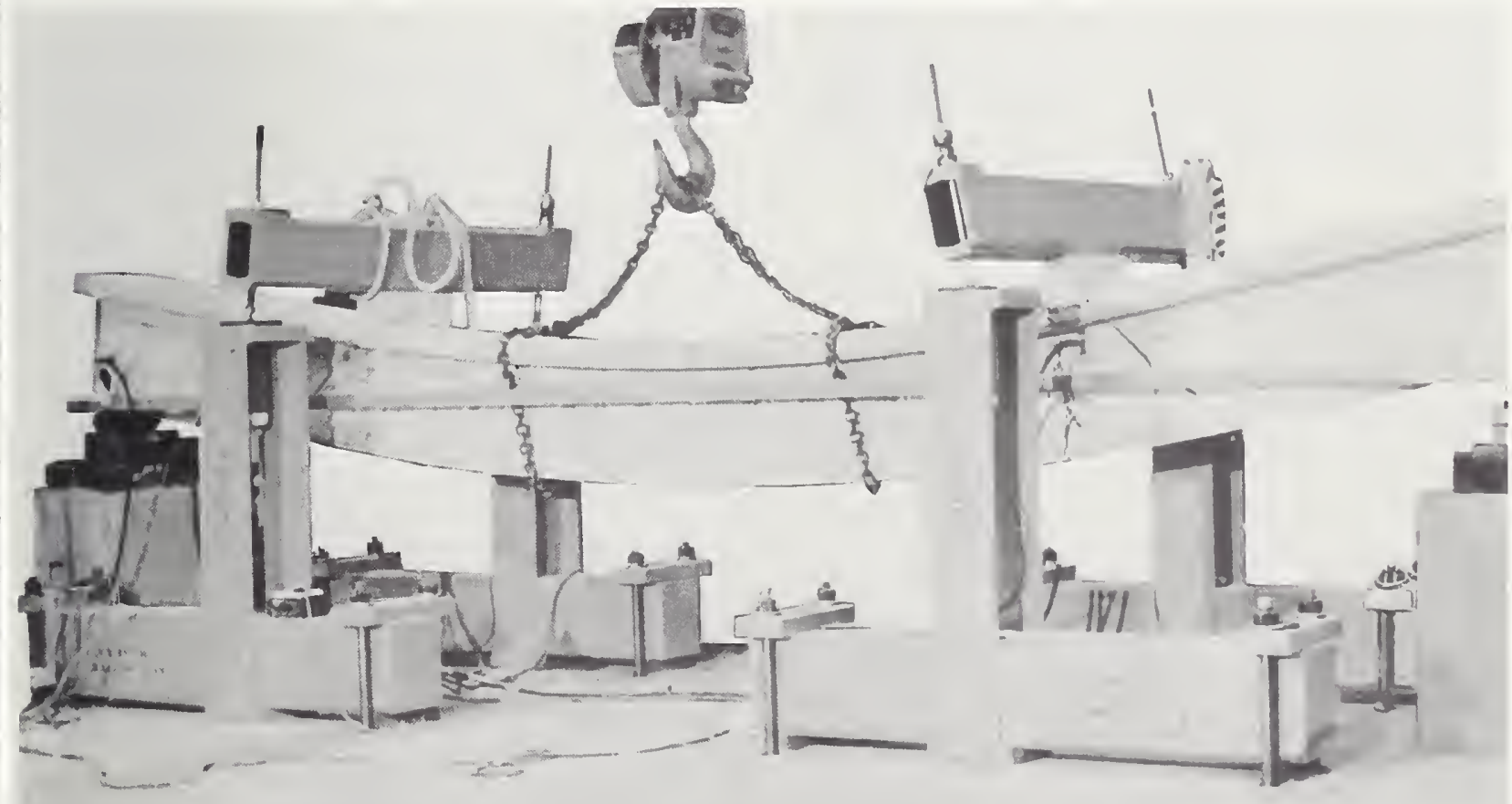

Figure 11. Pretensioned beam SB-t at ultimate load. 
post-tensioned bar were sheared off while the beam was being loaded. Beam SG-2 failed by complete separation of the interface of the tensile and compressive elements in the shear zone under load.

The expression $A_{s} t_{s y} d$ is here shown to be a valid index for an ordering of the overall load response for the beams in this investigation. It can also be seen in table 1 that the moment index $\left(A_{s} f_{s y} d\right)$ values are in good general agreement with the respective measured ultimate moments for all the beams failing in tension. Therefore, the moment index is a means by which a comparison can be made of the tendon sizes required to produce equal load response and capacity for split-beams and monolithic beams. The moment index for the monolithic beams ( $R U-1$. RU-2) is 755 in-kips and the tendon size is $0.37 \mathrm{sq}$ in. With these values as references, the required tendon size for equal performance by the split beam is,

$$
A_{s}=\frac{755 \text { in-kips }}{f_{\text {sy }} d}
$$

With the type of steel used for the post-tensioned beams, the tendon size for the split-beam is found to be $0.30 \mathrm{sq}$ in. This is a reduction of approximately 20 percent below the size for the monolithic beam.

An analysis of the principal properties of the stress block was conducted to evaluate the performance of the concrete at ultimate load. It has been demonstrated in laboratory tests [3] that the shape of the stress block at the ultimate capacity of a beam varies with the strength of the concrete. The shape of the stress block varies from nearly trapezoidal for low strength concretes in the 2000 psi class to nearly triangular for high strength concretes in the $7000 \mathrm{psi}$ class. The stress block has been found to be nearly parabolic for 5000 psi concrete. However, in determining the ultimate strength of beams, the exact shape of the stress block is not as important as the magnitude and location of the internal compressive force. This force can be defined and located in terms of three

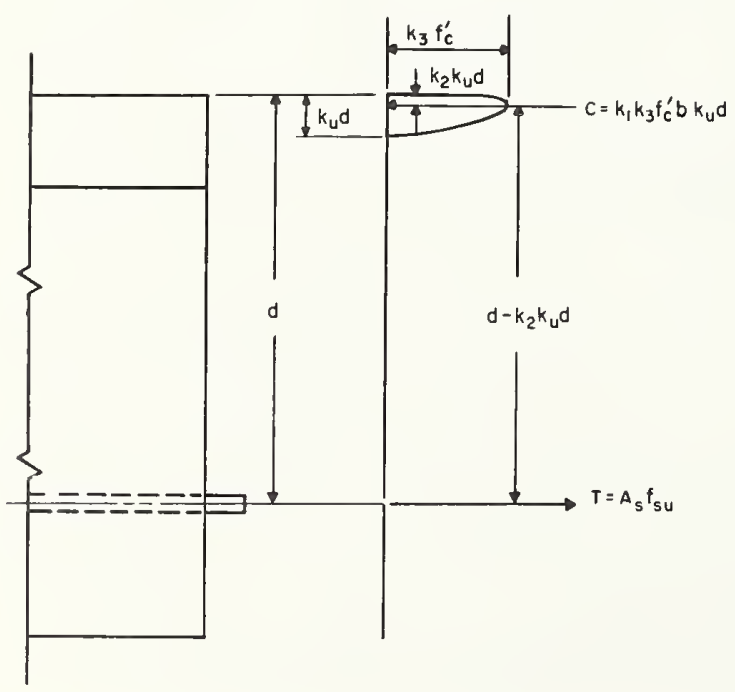

Figure 12. Stress conditions at ultimate load. parameters [4], $k_{1}, k_{2}$, and $k_{3}$. The parameter $k_{1}$ is defined as the ratio of the average compressive stress to the maximum compressive stress of the concrete in the compression zone of the beam at ultimate. The parameter $k_{2}$ is defined as the ratio of the depth to thc line of action of the resultant compressive force to the depth to the neutral axis. Parameter $k_{3}$ is defined as the ratio of the maximum compressive strength of the concrete in flexure to the cylinder strength.

The assumed stress conditions at ultimate load are shown in figure 12. The expression for the ultimate resisting moment is:

$$
M_{u}=A_{s} f_{s u}\left(d-k_{2} k_{u} d\right)=f_{s u} p b d^{2}\left(1-k_{2} k_{u}\right) .
$$

An expression for $k_{u}$ is obtained from the equilibrium of forces.

$$
k_{u}=\frac{p f_{s u}}{k_{1} k_{3} f^{\prime}} .
$$

Substituting eq (2) into eq (1) and dividing both sides by $f_{c}^{\prime} b c^{2}$ gives:

$$
\frac{M_{u}}{f^{\prime}{ }_{c} b d^{2}}=\frac{p f_{s u}}{f^{\prime}{ }_{c}}\left[1-\left(\frac{k_{2}}{k_{1} k_{3}}\right)\left(\frac{p f_{s u}}{f_{c}^{\prime}}\right)\right] .
$$

Equation (3) is a convenient relationship for evaluating the expression $\frac{k_{2}}{k_{1} k_{3}}$ by using the measured properties of a beam. The relationship shown in eq (3) , was studied using the measured ultimate moments and

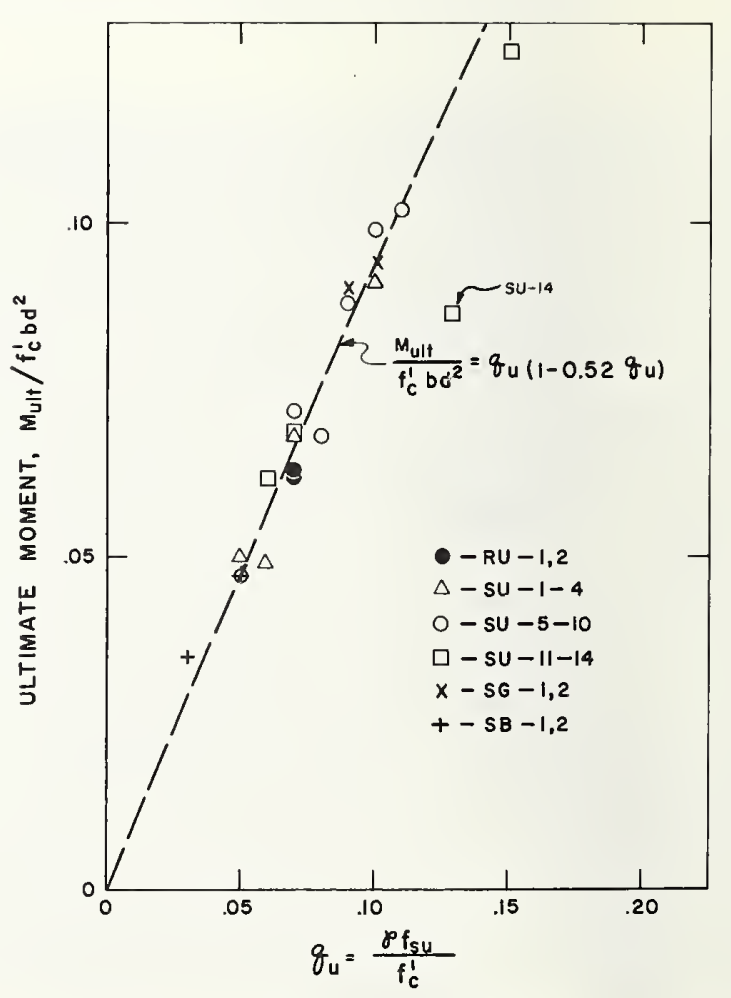

FIGLRE 13. Relationship betueen ultimate moment and qu. 
measured steel stresses at failure. The results are the plotted points shown in figure 13. The curve shown by dashed line in this figure was developed from the results of a study by Janny, Hognestad, and McHenry $\left[{ }^{5}\right]$ with rectangular beams covering five types of reinforcement. This curve represents the relationship in eq 3 for a value of $\frac{k_{2}}{k_{1} k_{3}}$ equal to 0.52 . The plotted points in figure 13 are in close agreement with the curve. This indicates that the basic characleristics of the stress block at ultimate load for the Tee beams in this investigation are similiar to those for the rectangular beams studied by Janny et al. It also indicates that the unusually low steel ratios, tendon location, and initial stress gradient discontinuity in the split-beams had no adverse effect on the ultimate load performances of these beams over a wide range of concrete strengths in the compressive elements (flange sections).

As would be expected for beams failing in tension, the strength of the concrete in the compression zone had little if any effect on the ultimate capacity of the beams. In this study only a rather general trend may be noted in a comparison of concrete strengths and ultimate moments for beams in the 925 in-kip moment index group (SU-5 thru SU-14). However, when the results for the beams in the 650 in-kip index group (SU-1 thru SU-4) were considered together with those of the 925 index group, no direct linear correlation of concrete strength and ultimate moment was found.

\section{Discussion}

The principal differences between the split-beams and the conventional monolithic beams in this study were in the initial prestress parameters allowed by the methods of construction. However, it was found that even with different initial prestress parameters, beams having the same ultimate capacity showed essentially the same overall flexural response to loading. The index $A_{s} f_{s y} d$, which was used to categorize the beams in relation to a scale of load response and capacity is essentially a measure of the internal resistant moment capacity for under-reinforced beams. The very close agreement between the index values and the respective measured ullimate moments for the Tee beams can be explained by considering the factors in the moment index expression. The factor $d$ is approached within 10 percent by the actual moment arm at ultimate and the actual stress in the steel is somewhat greater than the yield strength of the steel, $f_{s y}$, by a similar difference but opposite in direction to that for the $d$ factor. Consequently, the two departures from actual conditions conveniently compensate for each other.

Split-beams that had compressive elements with concrete strengths around 2000 psi showed erratic performances under loading. The failure mode for these beams was unpredictable and included brittle failures in the constant moment region and in the shear span for different beams. In order to avoid the risk of these type of failures, concrete strengths leekw 3000 psi should not be used in the compressive element of split-beams.

Due to the manner of construction and the design of the precompressed section, the split-bean enjoys the advantage of a reduced amount of reinforcing steel for the same overall flexural characteristics as compared with the conventional monolithic beam. However, it slould be emphasized that the comparison here is between a composite beam and a monolithic beam. Also, no tensile stresses were allowed in the slages of construction. It may be better to cvaluate the split-beams in relation to other composite beams. For example, it was stated earlier that the split-beam is a special case of composite construction where the construction joint is designed to coincide with the neutral axis of the composite section. Figure 14

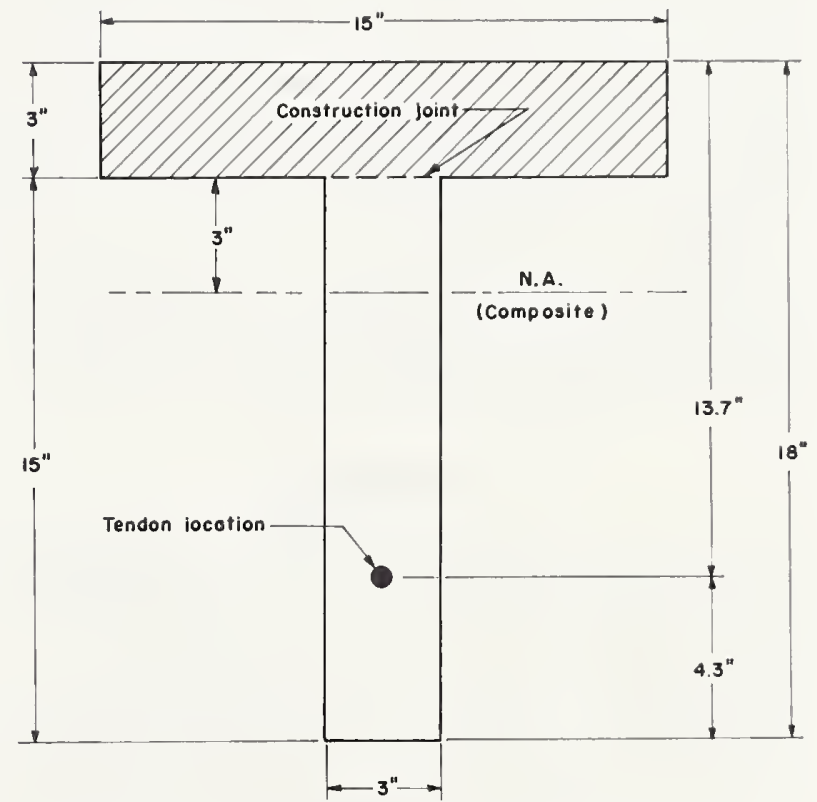

Figure 14. Cross section for conventional composite beam.

shows the cross section of a conventional composite beam where the construction joint is located at the intersection of flange and web. The dimensions of the cross section are the same as for the other beams in this investigation. To include this section in a comparison with the other beam seclions in this sludy, the basic prestressing parameters for the three types of beam construction features were computed with respect to the common moment index $A_{s} f_{s y} d=755$ inl-kips. These values are presented in table 2.

From the standpoint of performance, it is apparent that nothing is gained, in comparison with the splitbeam design, by locating the construction joint above the neutral axis of the cross section. In fact, for the same flexural characteristics, the required area of the reinforcing steel will increase with the distance of the construction joint above the neutral axis. Con- 
TABLE 2.-Computed prestressing denominators ${ }^{\text {a }}$ for posttensioned tee-beams of different construction with a common moment index of 755 in-kips

\begin{tabular}{|c|c|c|c|c|}
\hline $\begin{array}{c}\text { Construction } \\
\text { method }\end{array}$ & $F_{0}{ }^{b}$ & $d$ & $A_{s}$ & $f_{s e} / t_{s y}$ \\
\hline Monolithic & $\begin{array}{c}l b \\
45,000\end{array}$ & $\begin{array}{c}\text { in } \\
12.1\end{array}$ & $\begin{array}{l}i_{n} .^{2} \\
0.37\end{array}$ & 0.71 \\
\hline $\begin{array}{c}\text { Conventional } \\
\text { Composite }\end{array}$ & 33,750 & 13.7 & .33 & .61 \\
\hline Split-Beam & 27,000 & 14.7 & .30 & .53 \\
\hline
\end{tabular}

a For the same cross section, initial conditions, and steel bars for this study.

b Initial prestressing force.

versely, when the construction joint is located below the neutral axis the required area of the reinforcement will decrease as the distance of the construction joint to the neutral axis increases. The limiting. distance of the construction joint below the neutral axis will be affected by several practical considerations. Among these considerations are: (1) the minimum cross section needed for prestressing to a desired value; (2) the degree to which tensile cracks will be tolerated in the zone between the construction joint and the neutral axis within the working load range.

Although a strict economic evaluation for the practical use of split-beams was not within the scope of this study, the experience gained in preparing these specimens raises a serious question as to the balance between materials savings and the added cost of form work and construction handling.

\section{Conclusions}

Placing the construction joint at the neutral axis of a prestressed composite beam allows for an efficient prestress distribution over the cross section with no adverse effect on the performance of the beam.

Stirrups should be provided throughout the span length for these beams to prevent the development of extensive horizontal cracking just above the neutral axis in the region of maximum moment, and to serve as reinforcement against possible interface separation.

The product of the factors $A_{s} f_{s y} d$ was found to be a satisfactory index and very close indication of the ultimate moment for the beams in this investigation. Also, the test data agreed extremely well with the more refined relationship [ ] $\frac{M_{u i t}}{f^{\prime} b b d^{2}}=q_{u}\left(1-0.52 q_{u}\right)$.

Concrete strengths in the compression zone can be markedly reduced below that required for the prestressed element without significantly affecting the flexural characteristics of under-reinforced members. A practical lower limit would appear to be 3000 psi. The use of lightweight concrete in the compressive element should not be overlooked as an additional benefit.

The required amount of prestressing steel for the split-beam in this study was approximately 20 percent less than that for a monolithic beam. However, when compared with a conventional composite beam only a 9 percent reduction in steel was found in favor of the split beam.

This study was carried out at NBS within the scope of a broad program sponsored by the U.S. Department of the Navy (NAVFACENGCOM). The major program, which extended over several years, was principally concerned with investigations of new concepts for structural elements and systems in reinforced concrete.

\section{References}

[1] Amirkian, A., Split-beam prestressing, The Navy Civil Engineer 4, No. 11, 35 (1963).

[2] Bryson, J. O., Skoda, L. F., and Watstein, D., Flexural behavior of prestressed split-beam composite concrete sections, P.C.I. Journal 10, No. 3 (June 1965 ).

[3] Hognestad, E., Confirmation of inelastic stress distribution in concrete, Journal of the Structural Division, ASCE, Paper 1189, 83, No. ST-2 (March 1957).

[4] Billet, D. F., and Appleton, J. H., Flexural strength of prestressed concrete beams, A.C.I. Journal, June 1954, Proc. 50, pp. 837-854.

[5] Janney, J. R., Hognestad, E., and Mcllenry, D., Ultimate Flexural Strength of Prestressed and Conventionally Reinforced Concrete Beams, A.C.I. Journal 27, No. 6 (Feb. 1956). 


\section{Announcement of New Publications in Building Science Series}

Superintendent of Documents, U.S. Government Printing Office, Washington, D.C., 20402

Dear Sir:

Please add my name to the announcement list of new publications to be issued in the series: National Bureau of Standards Building Science Series.

Name

Company

Address

City State Zip Code

(Notification key N-339) 
, 


\section{NATIONAL BUREAU OF STANDARDS}

The National Bureau of Standards ' was established by an act of Congress March 3, 1901. Today, in addition to serving as the Nation's central measurement laboratory, the Bureau is a principal focal point in the Federal Government for assuring maximum application of the physical and engineering sciences to the advancement of technology in industry and commcrec. To this end the Bureau conducts rescarch and provides central national services in four broad program areas. These are: (1) basic measuremcnts and standards, (2) materials measurements and standards, (3) technological measurements and standards, and (4) transfer of technology.

The Bureau comprises the Institute for Basic Standards, the Institute for Materials Research, the Institute for Applied Technology, the Center for Radiation Research, the Ccnter for Computcr Sciences and Technology, and the Office for Information Programs.

THE INSTITUTE FOR BASIC STANDARDS provides the central basis within the United States of a complete and consistent system of physical measurement; coordinates that system with measurement systems of other nations; and furnishes essential services leading to accurate and uniform physical measurements throughout the Nation's scientific community, industry, and commerce. The Institute consists of an Office of Measurement Services and the following technical divisions:

Applied Mathematics-Electricity-Metrology-Mechanics-Heat-Atomic and Molecular Physics-Radio Physics "-Radio Engineering "-Time and Frequency "-Astrophysics "-Cryogenics."

THE INSTITUTE FOR MATERIALS RESEA RCH conducts materials research leading to inproved methods of measurement standards, and data on the properties of well-characterized materials needed by industry, commerce, educational institutions, and Government; develops, produces, and distributes standard reference materials; relates the physical and chemical properties of materials to their behavior and their interaction with their environments; and provides advisory and research services to other Government agencies. The Institute consists of an Office of Standard Reference Materials and the following divisions:

Analytical Chemistry-Polymers-Metallurgy_-Inorganic Materials_-Physical Chemistry.

THE INSTITUTE FOR APPLIED TECHNOLOGY provides technical services to promote the use of available technology and to facilitate technological innovation in industry and Government; cooperates with public and private organizations in the development of technological standards, and test methodologies; and provides advisory and research services for Federal, state, and local government agencies. The Institute consists of the following technical divisions and offices:

Engineering Standards-Weights and Measures - Invention and Innovation - Vehicle Systems Research-Product Evaluation-Building Research-Instrument Shops-Measurement Engineering-Electronic Technology-Technical Analysis.

THE CENTER FOR RADIATION RESEARCH engages in research, measurement, and application of radiation to the solution of Bureau mission problems and the problems of other agencies and institutions. The Center consists of the following divisions:

Reactor Radiation-Linac Radiation-Nuclear Radiation-Applied Radiation.

THE CENTER FOR COMPUTER SCIENCES AND TECHNOLOGY conducts research and provides technical services designed to aid Government agencies in the selection, acquisition, and effective use of automatic data processing equipment; and serves as the principal focus for the development of Federal standards for automatic data processing equipment, techniques, and computer languages. The Center consists of the following offices and divisions:

Information Processing Standards-Computer Information - Computer Services - Sys-

tems Development-Information Processing Technology.

THE OFFICE FOR INFORMATION PROGRAMS promotes optimum dissemination and accessibility of scientific information generated within NBS and other agencies of the Federal Government; promotes the development of the National Standard Reference Data System and a system of information analysis centers dealing with the broader aspects of the National Measurement System, and provides appropriate services to ensure that the NBS staff has optimum accessibility to the scientific information of the world. The Office consists of the following organizational units:

Office of Standard Reference Data-Clearinghouse for Federal Scientific and Technical Information "-Office of Technical Information and Publications-Library-Office of Public Information-Office of International Relations.

\footnotetext{
1 Headquarters and Laboratories at Gaithersburg. Maryland, unless otherwise noted: mailing address Washington, D.C. 20234

3 Located at 5285 Port Royal Road, Springfield, Virginia 22151.
} 


\section{U.S. DEPARTMENT OF COMMERCE} Washington, D.C. 20230

OFFICIAL BUSINESS

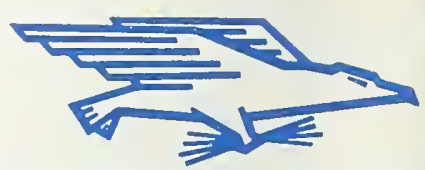

POSTAGE AND FEES PAID U.S. DEPARTMENT OF COMMERCE 

, 

